\title{
Comprehensive Application of Spatial and Reasoned Thinking in Physical Education
}

\author{
$\underline{\text { https://doi.org/10.3991/ijet.v16i16.24893 }}$
}

Bo Yang

Heilongjiang Bayi Agricultural University, Daqing, China

yb358666@163.com

\begin{abstract}
The traditional classroom teaching of physical education (PE) tends to be boring, stereotyped, and rigid; the teachers and students cannot choose between various teaching methods. Therefore, it is difficult to cultivate the creative thinking of students under the traditional model. To adapt to the needs of scientific development and modern society, it is important to explore a new PE model in combination with the knowledge in modern pedagogy, psychology, and kinesiology. This paper integrates the cultivation of spatial and reasoned thinking in PE. Specifically, the authors carried out questionnaire and field surveys on the understanding of students, teachers, and parents of PE in the primary schools of a region in China, and statistically analyzed their recognition of the PE teaching model improved in this research. The results show that: most students could adapt to the improved PE teaching model, and improve their thinking ability under that model; $89 \%$ of teachers and $72 \%$ of parents held a positive view of the improved PE teaching model. The research lays a theoretical basis for the improvement of traditional PE teaching model, and promotion of the diverse development of PE teaching.
\end{abstract}

Keywords - physical education (PE), spatial thinking, reasoned thinking, collaborative teaching

\section{Introduction}

The physical and mental health are the foundation for the development of students at different stages, and the important condition for the future development of the nation. As social productivity is increasing, people have gradually realized that $\mathrm{PE}$ is not just a concept that one should have during a certain period in one's life time, but a process that should be emphasized and strengthened throughout one's life [1-4]. School PE is an important content for the comprehensive development of pupils, middle and high school students, and college students; and it exerts an important role in the formation and improvement of their thinking ability, morality, aesthetics, intelligence, and physique [5-7]. PE not only needs to meet the needs of social development, but also should keep pace with the times and continuously optimize and reform according to the physical and mental health concepts of modern people [8-10]. Therefore, in the modern society with high survival stress, how to adopting a healthy life- 
style and cultivating lifelong exercise habits and minds will become important topics in school PE.

Nowadays, modern PE is no longer limited to traditional sports programs and physical exercises. Studies suggest that PE is also closely related to one's thinking ability and intelligence [11-14]. After the discovery, aiming at the improvement of intelligence and thinking ability, a few new concepts have been introduced in PE reform such as exploring new PE methods, constantly optimizing PE models, and strengthening students' physical fitness and various abilities [15-18]. The reform of the PE models needs to take into account the demands of both individuals and the society, and the focus should be shifted from the training of sports skills and physical exercises to the people-oriented modern education ideas, besides physical exercises, the focus of PE should also be laid on the internal transformation of people in humanity, consciousness, and thinking ability, etc. [19-22]. In addition, the spatial and reasoned thinking ability of students have a non-negligible influence on their intelligence and future development, therefore, incorporating them into PE and exploring a new PE model are extremely important research topics.

Based on these considerations, this paper takes realizing diversified PE methods and cultivating students' learning and exploring abilities as the education objectives, and studies the comprehensively application of spatial and reasoned thinking ability in PE from the perspectives of PE theories, teaching advantages, and teaching strategies.

\section{$2 \quad$ Methodology and feasibility analysis}

\subsection{Methodology}

In this study, literature review and questionnaire survey were conducted to explore the application of spatial and reasoned thinking ability in PE. At first, relevant documents were sorted out, papers and survey data were drawn from online information retrieval database, and materials related to student education, PE, student think pattern and reasoning ability were collected; then, combining with research results of psychology, pedagogy, and individual development theory, the collected data were integrated and counted.

The research target is the current status of PE in the primary schools of eastern region in China. Questionnaire surveys and interviews were conducted to investigate the understanding of three groups of subjects (students, teachers, and parents) of PE. For student respondents, 240 questionnaires were distributed, 240 were returned, among which 120 were valid questionnaires; for teacher respondents, 100 questionnaires were distributed and 100 valid questionnaires were returned; for parent respondents, 240 questionnaires were distributed and 240 valid questionnaires were returned. The effective rate of student questionnaires was $50 \%$ and the effective rates of teacher and parent questionnaires were $100 \%$. After the survey, the collected questionnaires and interview results were counted by mathematical statistical methods and the effective data were processed and analyzed. 


\subsection{Evaluation of the feasibility of the questionnaires}

Regarding the feasibility of the questionnaires, namely the degree of consistency between the research topic and the survey questions, $12 \mathrm{PE}$ experts were consulted. Logical analysis method was employed to prove that the questionnaires were logical and valid. Experts were asked to score the design and content of the questionnaires; the lowest score is 0 and the highest score is 10 . An evaluation score of less than 6 indicates that the questionnaire is considered infeasible; a score between 6 and 8 indicates that the questionnaire is basically feasible, and a score higher than or equal to 8 indicates that the questionnaire is feasible. The evaluation results are listed in Table 1.

Table 1. Feasibility evaluation of questionnaires

\begin{tabular}{|l|c|c|c|}
\hline & Logicality & Content integrity & Structural design \\
\hline Infeasible & 0 & 0 & 0 \\
\hline Basically feasible & 2 & 4 & 1 \\
\hline Feasible & 13 & 11 & 14 \\
\hline
\end{tabular}

\section{$3 \quad$ Research results and analysis}

\subsection{Basic facts of teachers}

The teachers' education level is one of the criteria for evaluating their cultural knowledge, professional knowledge, and basic theoretical knowledge. The education level of teacher respondents was counted and the results are shown in Table 2. Among the 50 primary school teachers, 8 of them has an education level of junior college or below, accounting for $16 \%$ of the teacher respondents; 24 of them has an education level of bachelor's degree, and 13 has an education level of master's degree, respectively accounting for $48 \%$ and $26 \%$; 5 respondent teachers are doctors, accounting for $10 \%$ of the teacher respondents, as shown in Figure 1, $84 \%$ of the elementary school teachers in this region have a bachelor's degree or above, the proportion of teachers with high education level is relatively large.

Table 2. Statistics of education level of teacher respondents

\begin{tabular}{|l|c|c|}
\hline \multicolumn{1}{|c|}{ Education level } & Number & Proportion \\
\hline Junior college or below & 16 & 16 \\
\hline Bachelor & 48 & 48 \\
\hline Master & 26 & 26 \\
\hline Doctor & 10 & 10 \\
\hline Total & 100 & 100 \\
\hline
\end{tabular}

In the survey, whether the teachers are graduates of normal colleges was investigated as well, and the results show that $76 \%$ of them are graduates of normal colleges, while $24 \%$ are not. Normal college graduates have received more targeted and sys- 
tematic training in professional skills and courses than those who are not graduated from normal colleges; however, trainings and work instructions in the primary schools can also improve these teachers' professional teaching ability. Overall, the education level and comprehensive quality of primary school teachers in this region are relatively good, which has a positive influence on students' basic knowledge lecturing, ideological education, and physical education.

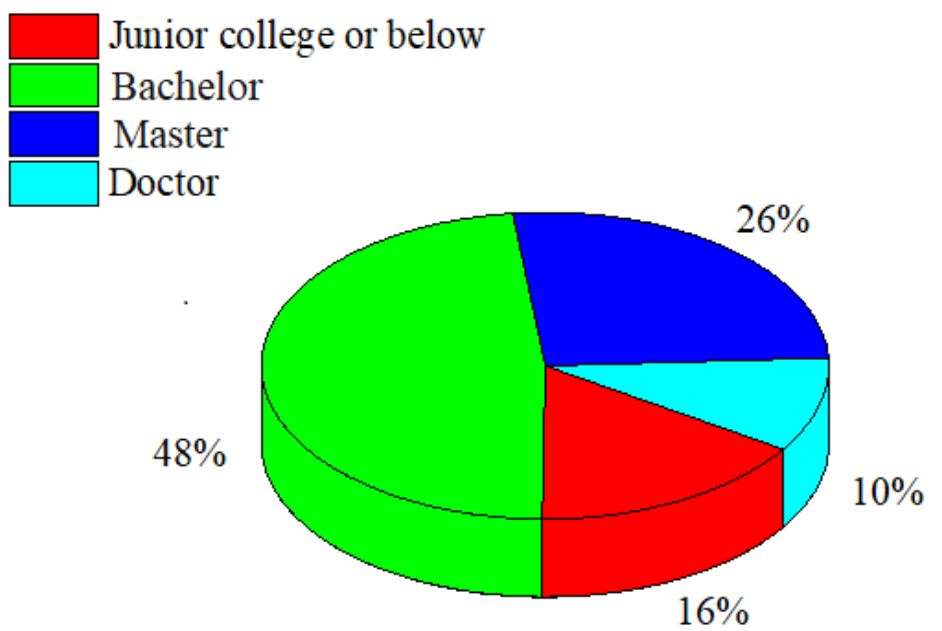

Fig. 1. Distribution of education level of teachers

Table 3. Profession of teachers

\begin{tabular}{|l|c|c|}
\hline \multicolumn{1}{|c|}{ Education background } & Number & Percentage \\
\hline Normal college & 76 & 76 \\
\hline Other profession & 24 & 24 \\
\hline Total & 100 & 100 \\
\hline
\end{tabular}

\subsection{Attitudes of teachers, parents, and students towards PE}

Survey results show that $61 \%$ of parents think that PE is very important, and $72 \%$ of teachers have the same attitude. This result indicates that both school teachers and parents are aware of the importance of PE to the personal development of students' physical and mental health. However, $19 \%$ of parents and $11 \%$ of teachers believe that $\mathrm{PE}$ only has an average influence on students' personal development; and $8 \%$ of parents and $8 \%$ of teachers think it is not important at all. Based on these findings we can see that most parents and teachers have a positive attitude towards PE (Figure 2).

The statistics of students' attitude towards PE is given in Figure 3. 52\% of students believe that PE reform is necessary, fun games and activities for cultivating students' spatial and reasoned thinking ability should be added to PE lessons; $31 \%$ of students 
expressed that current PE can basically meet their interest and needs; $19 \%$ of students didn't express their attitude clearly, and they didn't comment on the teaching content of PE.

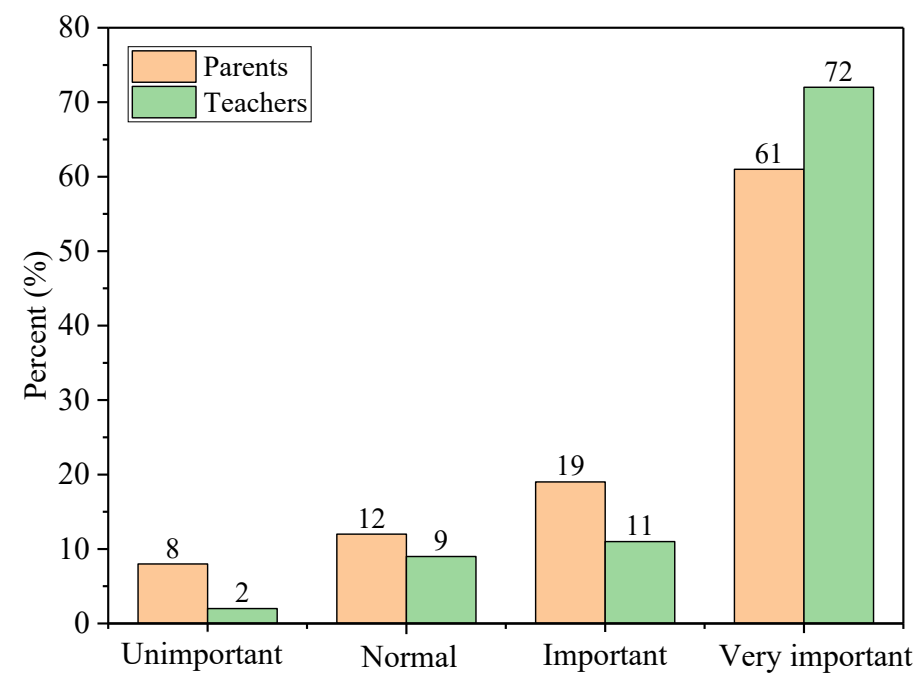

Fig. 2. Attitude of parents and teachers towards PE
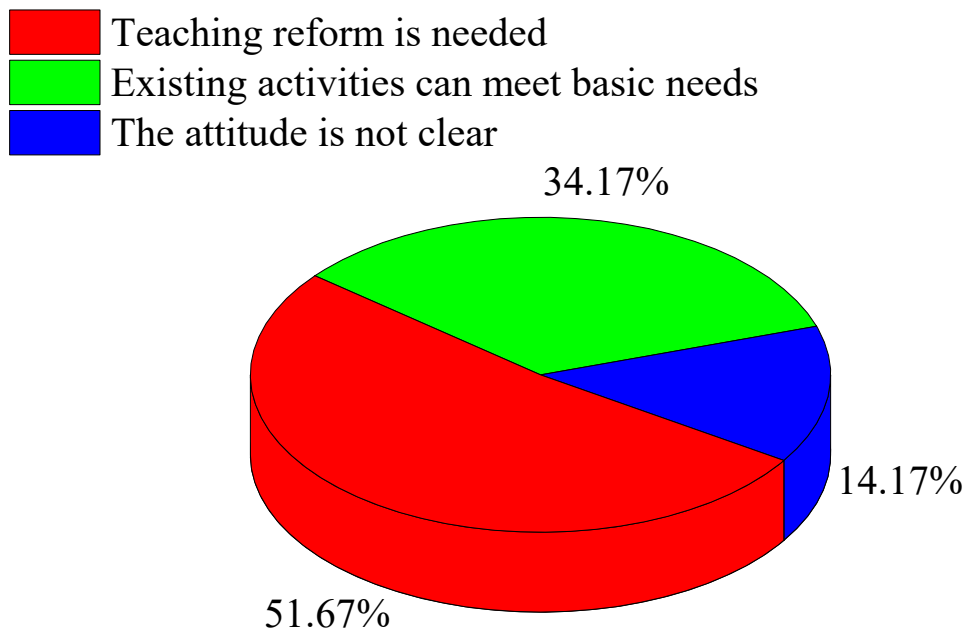

Fig. 3. Students' attitude towards PE

\subsection{Teaching content and goals of PE}

Traditional PE lessons generally adopt moderate intensity exercises that can strengthen students' body and improve their physical fitness and resistance. The integration of spatial and reasoned thinking ability in sports can ensure students have a 
good mood and develop their abilities in a balanced way. In primary school PE lessons, common teaching content includes gymnastics, track and field, ball games and other sports, etc. The survey results show that, gymnastics accounted for $31 \%$, track and field sports accounted for $28 \%$, ball games accounted for $29 \%$, and other sports accounted for $22 \%$ (Figure 4 ).

In the teaching content of PE lessons in elementary schools, the proportions of each sports type are not that different. The formation changes and free-standing exercises in gymnastics are suitable for most students, the amount of these exercises is relatively small, they generally do not have much demand for venue and equipment, and are quite easy to teach. Track and field and ball sports include basic movements such as walking, running, and jumping. However, only carrying out these sports programs would make the teaching content of PE lessons dull and not as varied, and this requires the teachers to optimize and innovate the PE lessons of students.

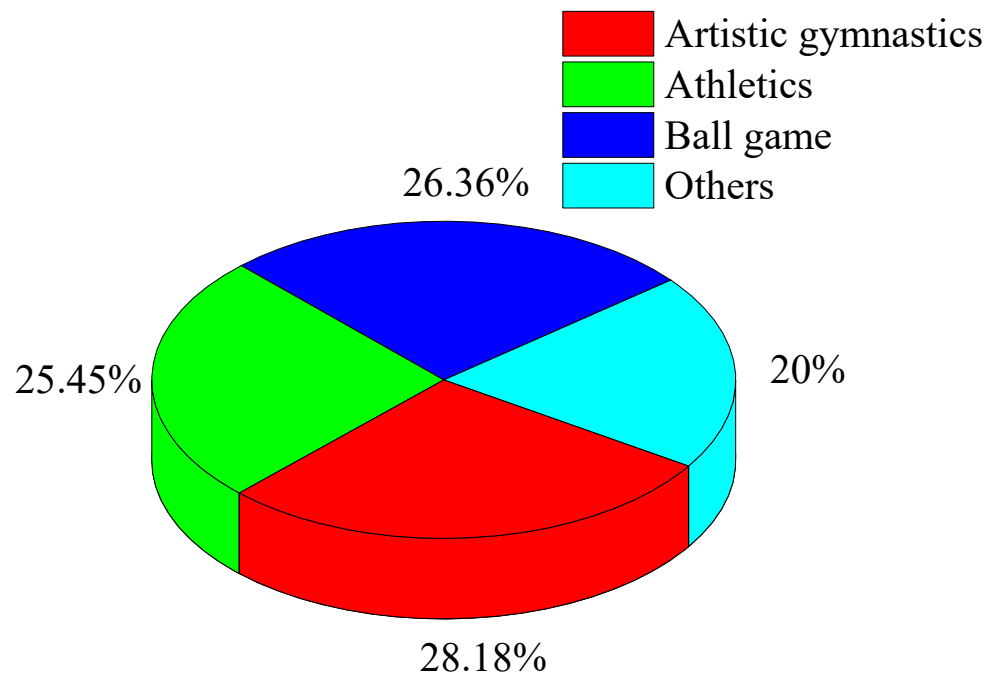

Fig. 4. Teaching content of PE lessons

To cultivate students' spatial and reasoned thinking ability, some fun games could be introduced into the PE lessons to carry out the problem-based sports learning. The teaching goals of PE include imparting sports knowledge, improving physical fitness, cultivating students' interest in sports, enhancing students' social adaptability, promoting mental health, and conducting ideological and moral education. According to the survey results of teachers' understanding of the teaching goals of PE shown in Figure $5,92 \%$ of teachers believe that the primary goal is to improve physical fitness; $87 \%$ of teachers believe its aim is to cultivate students' interest in sports; and $75 \%$ of them think it is to learn sports knowledge. According to the survey results, teachers generally believe that the impact of PE is the greatest on students' physical development; followed by that on the development of their social adaptability and intelligence, and the impact on their emotions and thinking ability came the last. 


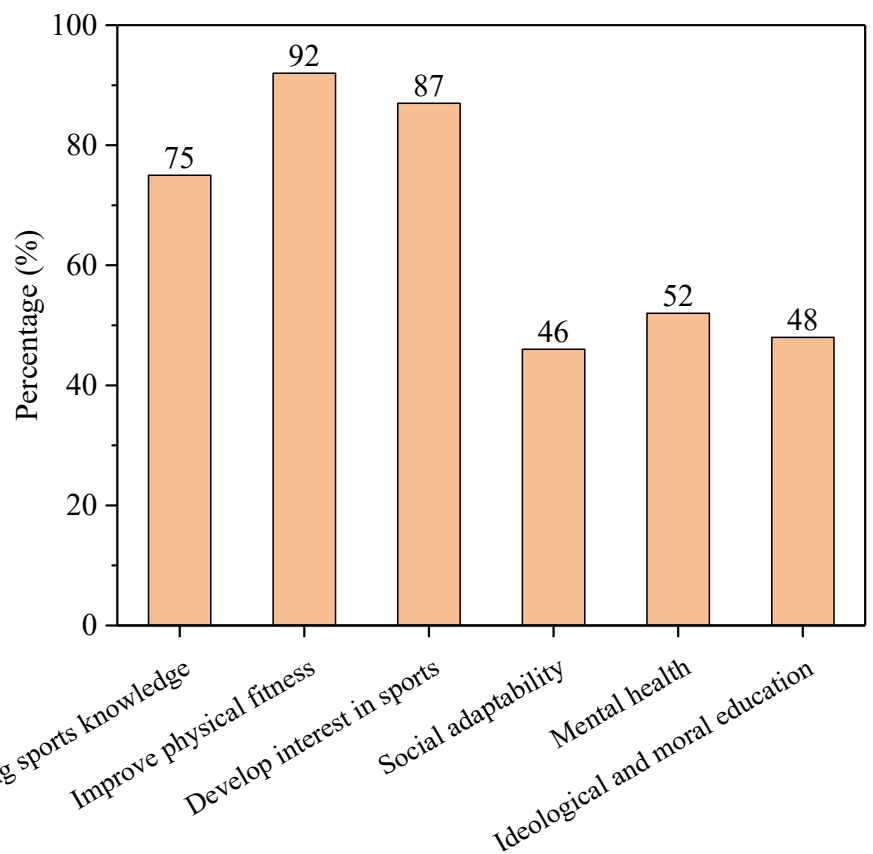

Fig. 5. Goals of physical education

\subsection{Application of spatial and reasoned thinking ability in PE}

In PE lessons, it's necessary to pay attention to the student's subject consciousness and establish PE teaching goals that can promote the comprehensive development of students. To integrate the training of spatial and reasoned thinking ability into PE, the first thing to do is to trigger students' interest in participating in sports and learning sports-related knowledge; moreover, theories of psychology and pedagogy could be combined to cultivate students' ability in discovering and solving problems, and help them build confidence to use the knowledge they learnt and the existing resources to cope with various problems, in this way, students' comprehensive thinking ability, reasoned thinking ability, and critical thinking ability could be enhanced. The second thing to do is to cultivate students' awareness and ability in autonomous learning; during PE lessons, after the instruction of teachers, students can adjust and strengthen themselves, and analyze and solve the problems. At the same time, it's also necessary to exercise and strengthen students' teamwork ability, instruct them to explore problems through collaboration, encourage them to communicate with each other about the solutions, and constantly get new skills from thinking and discussion.

During PE lessons, teachers need to well play the roles as instructors and regulators to ensure the smooth implementation of teaching activities. In view of students' individual ability in learning, recognition, and development, the reformed PE should follow the principles of universally applicable, open, inspiring, creative, and 
autonomous, etc. The teaching plan should be flexible and can be appropriately adjusted for different situations.

Elementary and middle school students generally have more curiosities to explore problems, integrating the cultivation of spatial and reasoned thinking ability into PE can further achieve the purpose of improving their physical fitness and promoting their comprehensive development. The newly proposed PE model that integrated thinking ability has the following aspects, as shown in Figure 6, (a) The creation of problem scenario and exercise conditions, which offers students with an environment for problem-solving so that they could apply the knowledge they leant to analyze problems; (b) The combination pedagogy and psychology, with improving students' spatial and reasoned thinking ability as one of the goals, the thinking ability exercise methods are combined with sports programs to create conditions for the intelligence sports; (c) Summarization, after PE lessons, summarize problems and new discoveries found during students' learning process or teachers' teaching process and form systematic theoretical knowledge; (d) Reflection after teaching.

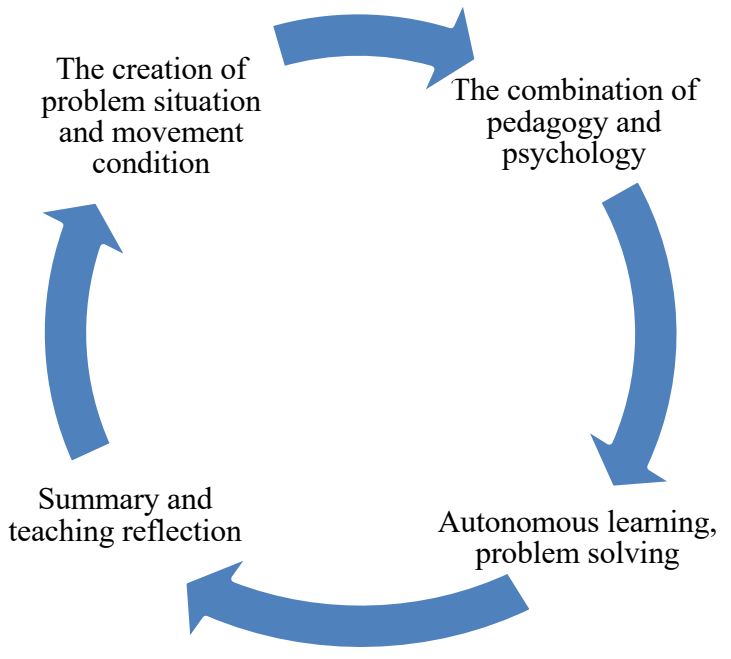

Fig. 6. The proposed new PE model

\subsection{Application of the proposed new PE model}

For the application effect of the newly proposed PE model that integrated the spatial and reasoned thinking ability, an evaluation was given following the flow chart shown in Figure 7. Moreover, combining with the survey results, we can figure out the recognition of students, teachers, and parents of the proposed PE model. 


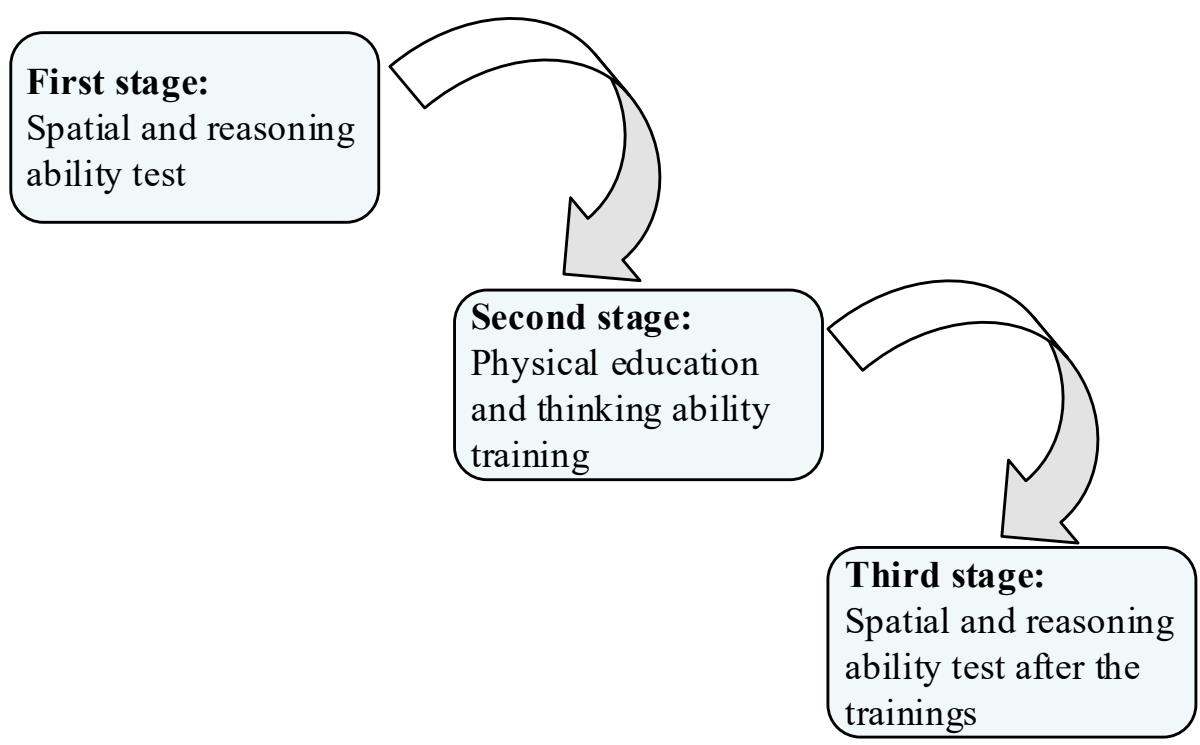

Fig. 7. Evaluation flow of the new PE model

Statistics of students' attitude towards the new PE model is shown in Figure 8. $68 \%$ of students like the reformed PE model very much, and they think it has obviously improved their spatial and reasoned thinking ability; $21 \%$ of students think the new model has improved their spatial and reasoned thinking ability to a certain extent; and $11 \%$ of them think the new model doesn't have much influence on the improvement of their spatial and reasoned thinking ability.

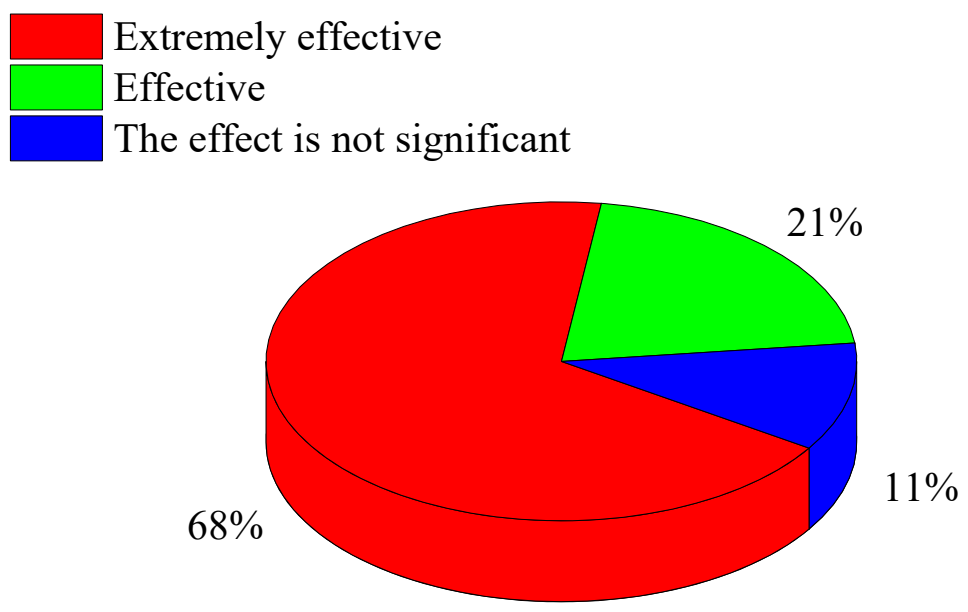

Fig. 8. Students' attitude towards to the new PE model 
Statistics of teachers' and parents' attitude towards the new PE model are shown in Figures 9 and 10. Among the teacher respondents, $74 \%$ of them believe that integrating the cultivation of spatial and reasoned thinking ability into PE can greatly improve students' physical fitness, intelligence, and thinking ability, which is conductive to their comprehensive development. $15 \%$ of them believe that PE reform is conducive to the improvement of students' comprehensive quality; $8 \%$ of them think PE doesn't have much influence on students' thinking ability, and $3 \%$ of them think that paying too much attention on PE has an adverse effect on students' learning of other basic knowledge. These results show that, the traditional ideas of some teachers need to be changed, and the schools should make efforts to update teachers' cognition and acceptance of modern education models.

Greatly promote the all-round development of students Promote the all-round development of students

No obvious difference with the traditional physical education Adverse effect

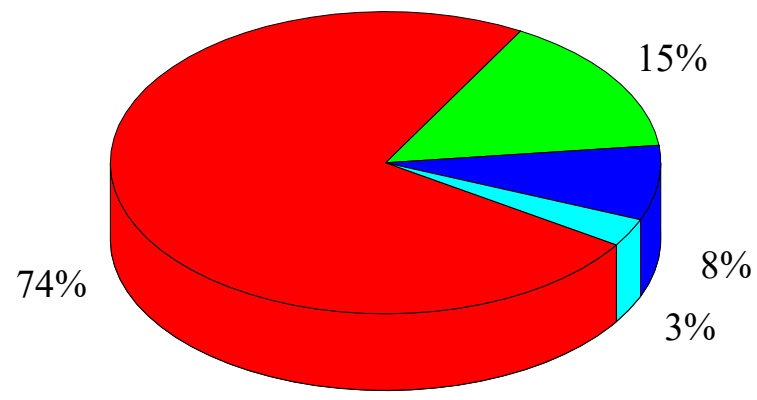

Fig. 9. Teachers' attitude towards to the new PE model

Among the parent respondents, $51 \%$ of them believe that integrating the cultivation of spatial and reasoned thinking ability into PE can greatly improve students' physical fitness, intelligence, and thinking ability; $21 \%$ of them hold a positive view and think that PE reform is conducive to the improvement of students' comprehensive quality; $23 \%$ of them think PE doesn't have much influence on students' thinking ability, and $5 \%$ of them believe the traditional PE lessons are enough for improving students' physical quality and PE reform would have a negative impact.

These results reveal that the cognition of some teachers and parents is quite traditional, and they fail to understand the influence of PE on the cultivation of students' comprehensive quality in the context of the fast-developing modern society, and schools need to make efforts to improve parents' cognition and acceptance of modern education models. 
Greatly promote the all-round development of students

Promote the all-round development of students

No obvious difference with the traditional physical education Adverse effect

$21 \%$

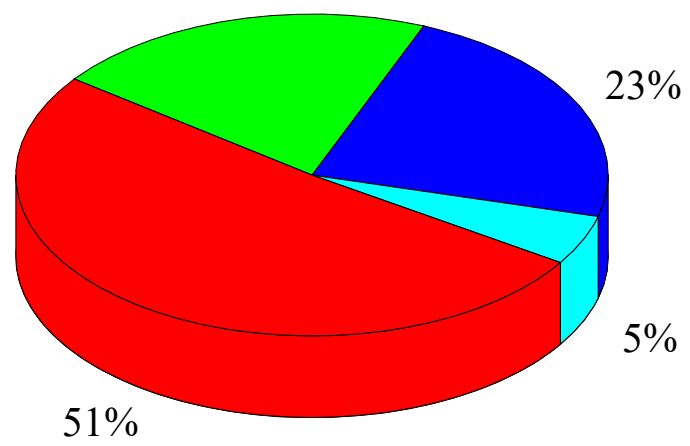

Fig. 10. Parents' attitude towards to the new PE model

\section{Conclusions}

Based on the theories of psychology, pedagogy, and kinesiology, this study took into account the social development trends and social requirements and proposed to apply spatial and reasoned thinking into PE. Through questionnaire survey, the current status of PE in primary schools and the situations after the new PE model had been applied were investigated, after carefully studied the survey results, the following conclusions were drawn:

1. The optimized PE model can trigger students' subjective initiative, cultivate their reasoned thinking ability and critical thinking ability, enhance their collaboration ability, so that they could adjust and regulate themselves, and discover and solve the problems.

2. $68 \%$ of students like the reformed PE model very much and think it has obviously improved their spatial and reasoned thinking ability; $21 \%$ of them think the new model has improved their spatial and reasoned thinking ability to a certain extent; and the rest of them think it doesn't have much influence on their thinking ability.

3. More than $70 \%$ of parents and teachers hold a positive attitude towards the new PE model, they think integrating the spatial and reasoned thinking exercises into PE is conducive to the long-term personal development of students.

\section{$5 \quad$ References}

[1] Zeng, Y.S. (2020). Evaluation of physical education teaching quality in colleges based on the hybrid technology of data mining and hidden markov model. International Journal of Emerging Technologies in Learning, 15(1), 4-15. https://doi.org/10.3991/ijet.v15i01.12533 
[2] Kao, C.C., Luo, Y.J. (2020). Effects of multimedia-assisted learning on learning behaviors and student knowledge in physical education lessons: using basketball game recording as an example. International Journal of Emerging Technologies in Learning, 15(1), 119-139. https://doi.org/10.3991/ijet.v15i01.11393

[3] Kim, S.Y. (2020). A Qualitative Exploration of Effective Creative/Convergence Type of Class in Middle and High School Physical Education Classes, International Journal of Online and Biomedical Engineering, 16(15), 23-33. https://doi.org/10.3991/ijoe.v16i15 .18721

[4] Chaichitwanidchakol, P., Feungchan, W. (2020). Design and Implementation of Interactive Mobile Application for Autistic Children in Physical Education Class, International Journal of Interactive Mobile Technologies, 14(14), 134-147. https://doi.org/10.3991/ ijim.v14i14.15477

[5] Parkes, D. (2007). A Prisoners' Charter: Reflections on Prisoner Litigation under the Canadian Charter of Rights and Freedoms. UBCL Rev., 40, 629.

[6] Vašíčková, J., Neuls, F., Frömel, K. (2010). Comprehensive test in school physical education at secondary schools in the Czech Republic-Standardization and verification. Acta Gymnica, 40(4): 7-14.

[7] Sabiston, C.M., Pila, E., Pinsonnault-Bilodeau, G., Cox, A.E. (2014). Social physique anxiety experiences in physical activity: a comprehensive synthesis of research studies focused on measurement, theory, and predictors and outcomes. International Review of Sport and Exercise Psychology, 7(1): 158-183. https://doi.org/10.1080/1750984x.2014. $\underline{904392}$

[8] Centeio, E.E., Erwin, H., Castelli, D.M. (2014). Comprehensive school physical activity programs: Characteristics of trained teachers. Journal of Teaching in Physical Education, 33(4): 492-510. https://doi.org/10.1123/itpe.2014-0066

[9] Sterdt, E., Liersch, S., Henze, V., Röbl, M., Suermann, T., Krauth, C., Walter, U. (2014). Implementing daily physical education in primary school-potentials and barriers from the involved actor's point of view. Gesundheitswesen (Bundesverband der Arzte des Offentlichen Gesundheitsdienstes (Germany)), 77(4): 269-275. https://doi.org/10.1055/s$\underline{0034-1377035}$

[10] Li, Z. (2011). Study of Impacts on Students' Comprehensive Developments by College Physical Education. In Advanced Materials Research, 187: 809-814. https://doi.org/10. 4028/www.scientific.net/AMR.187.809

[11] Bridges, P.H., Carter, V.M., Phillips, T., Conwell, R., Hensley, B., Repko, A., Johanson, M. A. (2018). Assessment of the Reliability and Validity of a Clinical Evaluation Instrument in Physical Therapy Education. Journal of Physical Therapy Education, 32(1): 26-37. https://doi.org/10.1097/JTE.0000000000000021

[12] Carson, R. (2012). Certification and duties of a director of physical activity. Journal of Physical Education, Recreation \& Dance, 83(6): 16-29. https://doi.org/10.1080 /07303084.2012.10598790

[13] Beaulieu, L., Butterfield, S.A., Pratt, P. (2009). Physical Activity Opportunity in United States Public Elementary Schools. ICHPER-SD Journal Of Research, 4(2): 33-36.

[14] Dragnev, Y.V. (2012). Modern education of future teacher of physical culture in the conditions of informatization of educational space. Pedagogics, psychology, medicalbiological problems of physical training and sports, (3): 53-56. https://doi.org/ $\underline{10.1149 / 1.3267872}$

[15] Brown, S.R., Phuong, A. (2015). Comprehensive examinations in physical therapy education programs. Physiotherapy, 101: e181-e182. https://doi.org/10.1016/j.physio. $\underline{2015.03 .339}$ 
[16] Egan, C.A., Webster, C.A., Stewart, G.L., Weaver, R.G., Russ, L.B., Brian, A., Stodden, D.F. (2019). Case study of a health optimizing physical education-based comprehensive school physical activity program. Evaluation and program planning, 72: 106-117. https://doi.org/10.1016/j.evalprogplan.2018.10.006

[17] Doolittle, S.A., Rukavina, P.B. (2014). Case study of an institutionalized urban comprehensive school physical activity program. Journal of Teaching in Physical Education, 33(4): 528-557. https://doi.org/10.1123/jtpe.2014-0073

[18] Utley, C., Brown, S.R., Robel, J.S. (2016). Effect of clinical experience on comprehensive examination performance in a physical therapist education program. Journal of Physical Therapy Education, 30(2): 38-44. https://doi.org/10.1097/00001416-201630020-00008

[19] Rahmat, A., Jani, J., Salimin, N., Khalid, N.H.M., Salleh, O. (2012). Comprehensive assessment module for first aiding physical and health education. Ovidius University Annals, 12(1): 54-59.

[20] Marakushyn, A., Piddubnyi, O., Konovalov, V., Kyrpenko, V. (2015). Formation and diagnostics levels of educational abilities of students in physical education. Slobozhanskyi herald of science and sport, 1(45): 68-75. https://doi.org/10.15391/snsv.2015-1.014

[21] Morgan, P.J., Hansen, V. (2008). Physical education in primary schools: Classroom teachers' perceptions of benefits and outcomes. Health education journal, 67(3): 196-207. https://doi.org/10.1177/0017896908094637

[22] Lee, G.H., Im, Y.S. (2000). A study on interest and application ability in meal management of the middle school students. Korean Journal of Human Ecology, 9(3): 383394. https://doi.org/10.1016/S0272-6386(97)90370-X

\section{Authors}

Bo Yang, graduated from Chengdu Sport University with a master's degree, majoring in physical education and training. Yang Bo is now a teacher and lecturer in the Sports Teaching and Research Department of Heilongjiang Bayi Agricultural University, mainly engaged in the teaching of university PE courses, and concurrently serving as the head coach of the swimming team of Heilongjiang Bayi Agricultural University. During the 2008-2020 period as the head coach, the team members had won 2 gold medals, 1 silver medal and 4 bronze medals in the University Games of Heilongjiang Province. Yang Bo had published 12 provincial-level papers and 1 monograph, and had 1 patent for utility models.

Article submitted 2021-06-18. Resubmitted 2021-07-22. Final acceptance 2021-07-23. Final version published as submitted by the authors 